100 Gr. milchsaurer Kalk (nach Gobley angefertigt) mit $500 \mathrm{Gr}$. in Wasser aufulösen und zu filtriren, wie auch andern Theils $68 \mathrm{Gr}$. reines schwefelsaures Eisenoxydul in $500 \mathrm{Th}$. kaltem destillirtem Wasser. Beide Solutionen werden sodann im Glasgefässe unter Zusatz von etwas Milchsäure im Marienbade erhitzt unter öfterem Umrühren. Nach der Zerlegung wird durchs Filtriren der Gyps getrennt, verdunstet und das Product zur Krystallisation gebracht, welches mit Alkohol abgespühlt, ferner zwischen Filtrirpapier getrocknet wird. (Journ. de Pharm. et de Ch. Avril 1846. pag. 272 etc.) Witting.

(Vergl, dies. Arch. B. 47. p. 270, woselbst wesentheh die gleiche Vorschrift, unabhángig von dem Vorschlage Lepage's, gegeben worden ist.) Die Red.

\title{
Erkennung der Blausäure in thierischen Materien ohne Anwendung der Destillation.
}

A. T a ylor giesst von der verdächtigen Flüssigkeit oder breiigen u.s. w. Materie in ein Uhrglas und stürzt ein anderes Uhrglas, dessen innere Fläche mit salpetersaurer Silberlösung befeuchtet ist, darüber. Bei Gegenwart von Blausäure (soll wohl heissen: von nicht geringen Mengen fr ei er Blausäure - ?) beschlägt die benetzte Glasfläche in $10-15$ Minuten weiss durch Bildung von Cyansilber. Natürlich muss der weisse Beschlag auf Cyansilber geprüft werden. Aus dem Englischen in Buchn. Repert. f. d. Ph. 44. 1.90. B.

\section{Valeriansäure.}

Chancel konnte die von Loewig beobachtete Bildung von reinem Valeron bei der trockenen Destillation der Valeriansäure (valeriansaurer Salze) nicht bestätigen. Bei der Destillation von valeriansaurem Baryt erhielt er eine Menge brennbarer Gasarten, eine Fluissigkeit, welche er Valeral nennt und einen Riickstand von kohlensaurem Baryt mit Kohle. Das durch wiederholte Rectification gereinigte Valeral ist klar, farblos, sehr dünnfluissig, siedet bei $110^{\circ}$, seine Dichtigkeit ist bei $22^{\circ} 0,820$, es besitzt einen brennenden Geschmack, durchdringenden Geruch, ist unlöslich in Wasser, mischbar mit Alkohol, Aether und ätherischen Oelen, leicht entzündlich und verbrennt mil glänzender Flamme mit bläulichem Rande. Oxydirende Körper verwandeln das Valeral in Valeriansäure; Salpetersäure erzeugt damit eine der Buttersalpe- 